\title{
[4]Cyclofluorene: unexpected influence of alkyl chain length
}

\author{
Lambert Sicard, ${ }^{[\mathrm{a}]}$ Olivier Jeannin, ${ }^{[\mathrm{a}]}$ Joëlle Rault-Berthelot, ${ }^{[\mathrm{a}]}$ Cassandre Quinton*${ }^{[\mathrm{a}]}$ and Cyril Poriel ${ }^{*[\mathrm{a}]}$ \\ [a] M. Lambert Sicard, Dr Olivier Jeannin, Dr Joëlle Rault-Berthelot, Dr Cassandre Quinton* and Dr Cyril Poriel* \\ Univ Rennes, CNRS, ISCR- UMR 6226, F-35000 Rennes, France
}

*E-mail:cyril.poriel@univ-rennes1.fr, cassandre.quinton@univ-rennes1.fr

ABSTRACT: Molecular nanorings have attracted a lot of interest the last ten years. Here we present the study of a new example of [4]cyclofluorene, with ethyl chains on the bridgeheads. Its molecular structure was established by solution NMR spectroscopy and single-crystal X-ray diffraction. Three successive oxidation processes and one reversible reduction were observed via cyclic voltammetry. The optical properties were characterized both in solution and film by UV-visible spectroscopy, stationary and timeresolved fluorescence. It was found that this [4]cyclofluorene displays different characteristics compared to the other [4]cyclofluorenes substituted by methyl or propyl chains: a simple modification of the chain length induces a non-negligible effect on the emission properties which must be linked to the specific arrangement of the fluorene units. Furthermore, single-crystal X-ray diffraction reveals the formation of a pseudo-tubular solid state arrangement of fully symmetrical ring structures, which was not observed for the other members of the [4]cyclofluorenes family. This feature, never discussed to date, could open the way to the modulation of properties of cyclofluorenes through alkyl chain engineering.

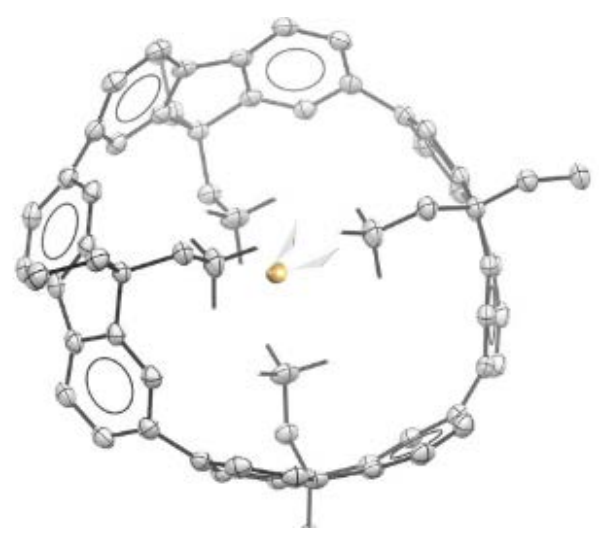

\section{INTRODUCTION}

Cyclo-para-phenylenes (CPP), association of phenylene units via para linkages to form a so-called nanoring, have met a great interest since the first example reported by Jasti and Bertozzi in 2008. ${ }^{[1]}$ This fantastic contribution has paved the way to a new research field, namely the molecular nanorings. ${ }^{[2-7]}$ Many CPP-like nanorings, constructed with various key building units such as pyrene, ${ }^{[8]}$ naphthalene, ${ }^{[9]}$ porphyrin ${ }^{[10]}$ and stilbene ${ }^{[11]}$ have been then further synthesised and studied. The cyclic association of these units leads to highly appealing properties, which are very different from those of their linear counterparts. ${ }^{[2,12-13]}$ Considering that linear organic semi-conductors are the molecular pillars which have allowed the development of organic electronics, investigating their cyclic counterparts appears as an exciting challenge. ${ }^{[14-15]}$ Of all the building units used in organic electronics, the fluorene undoubtedly holds a particular place notably due to its remarkable fluorescence properties. Its chemistry is at the origin of the rise of Organic Light-Emitting Diodes. ${ }^{[16-20]}$ The first examples of cyclofluorenes have been reported in late 2015 and in an almost concomitant manner by the groups of Yamago and Huang. ${ }^{[21-22]}$ In these examples, the four fluorene units have their bridgeheads respectively substituted by methyl ${ }^{[21]}$ (called herein [4]C-diMe-F) and propyl ${ }^{[22]}$ ([4]C-diPr-F) groups. In linear oligofluorenes, the size of these alkyl chains has an influence on the physical properties (solubility, decomposition temperature, phase transitions, melting point, etc.), the solid state packing and the charge carrier properties but has no influence on the electronic properties at the molecular level. In the present work, we report the unforeseen effect of a chain length modification (substitution of the bridgeheads with ethyl chains) on the structural and emission properties of a new example of a cyclic tetrafluorene, namely the [4]cyclo-9,9-diethyl-2,7-fluorene ([4]C-diEt-F). To the best of our knowledge, such an effect has never been reported to date in the literature linked to CPP-like molecules. In addition to a structure-properties relationship 
study with its linear counterpart [4]L-diEt-F, we also report herein some unexplored aspects of cyclofluorenes which shed further light on the impact of the fluorene cyclic association. This work shows the great potential diversity one can expect from the emerging cyclofluorenes family.

\section{RESULTS AND DISCUSSION}

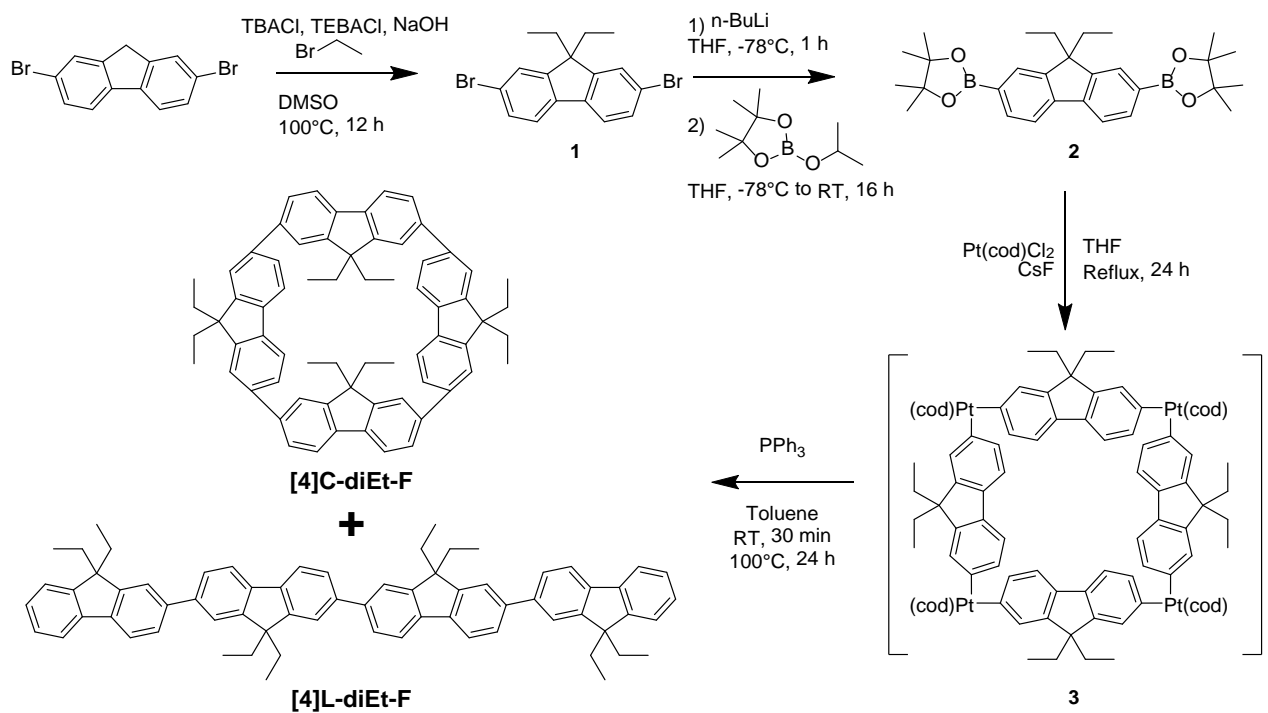

Scheme 1. Synthetic route to [4]C-diEt-F and [4]L-diEt-F.

The synthetic pathway to [4]C-diEt-F, of which the strain energy $(72.4 \mathrm{kcal} / \mathrm{mol})$ was found to be very close to that of [4]C-diMe-F $(72.1 \mathrm{kcal} / \mathrm{mol})^{[21]}$ and [4]C-diPr-F $(79.8 \mathrm{kcal} / \mathrm{mol}){ }^{[22]}$ and its linear analogue [4]L-diEt-F is similar to the method described by Huang et al. ${ }^{[22]}$ It is inspired by the pioneer work of Yamago et al. ${ }^{[6,23]}$ and further contribution from Isobe et al. ${ }^{[2]}$ The square shape tetranuclear platinum complex 3 , which could not be isolated due to its insolubility, was obtained by stirring the diboronic fluorene 2 with $\mathrm{Pt}(\operatorname{cod}) \mathrm{Cl}_{2}$ and cesium fluoride in a refluxing THF solution for $24 \mathrm{~h}$. The carefully dried crude containing $\mathbf{3}$ was treated with triphenylphosphine in toluene heated to $100^{\circ} \mathrm{C}$ for $24 \mathrm{~h}$ to give [4]C-diEt-F and [4]L-diEt-F with respective yields of $12 \%$ and $5 \%$. The two compounds were separated by slow elution through two consecutive silica gel columns. It is interesting to note that the previously described procedure is quite different from the one put forth by Yamago et al for the synthesis of [4]C-diMe-F, ${ }^{[21]}$ which uses norbornadiene ligands instead of cyclooctadiene in very dilute environments, and a distannic derivative instead of a diboronic. In fact, using $\mathrm{Pt}(\operatorname{cod}) \mathrm{Cl}_{2}$ in a dilute environment $(3 \mathrm{mmol} / \mathrm{L}$ ), Yamago and co-workers reported the almost exclusive observation of a trinuclear platinum complex and the subsequent [3]cyclo-9,9-dimethyl-2,7-fluorene. On the other hand, no trace of trimer molecules was observed by either Huang or us with the same ligand but in a concentrated environment (26 $\mathrm{mmol} / \mathrm{L}$ ). Given that the formation of the intermediate platinum complexes is under thermodynamical control, it is doubtful the nature of the precursor (stannic vs boronic) has any influence. Fujita et al have shown that the degree of concentration can drive the formation of the complex towards a triangle or rectangle shape. ${ }^{[25]}$ It also seems possible that the chain length plays a role in the relative stabilities of the trimer and tetramer complexes. Indeed, if the triangle complex is stable with the methyl chains, the longer alkyl chains (ethyl, propyl) could destabilize the triangle in favour of the square complex. However, a systematic study would be required in order to precisely establish these parameters. In our case as well as Huang's, the fact that only tetramers are observed (no other sizes of linear or cyclic compounds such as two-, three- or five-units oligofluorenes were detected) suggests that both the cyclic and linear products (with four units) come from the same tetranuclear platinum complex through two distinct elimination mechanisms. It remains however unclear how the two required protons are fed to the linear molecule. Confirming this hypothesis would require the isolation of $\mathbf{3}$ which was unfortunately found to be insoluble. Changing the bridgeheads to bigger alkyl chains could improve the solubility of the platinum intermediate. 


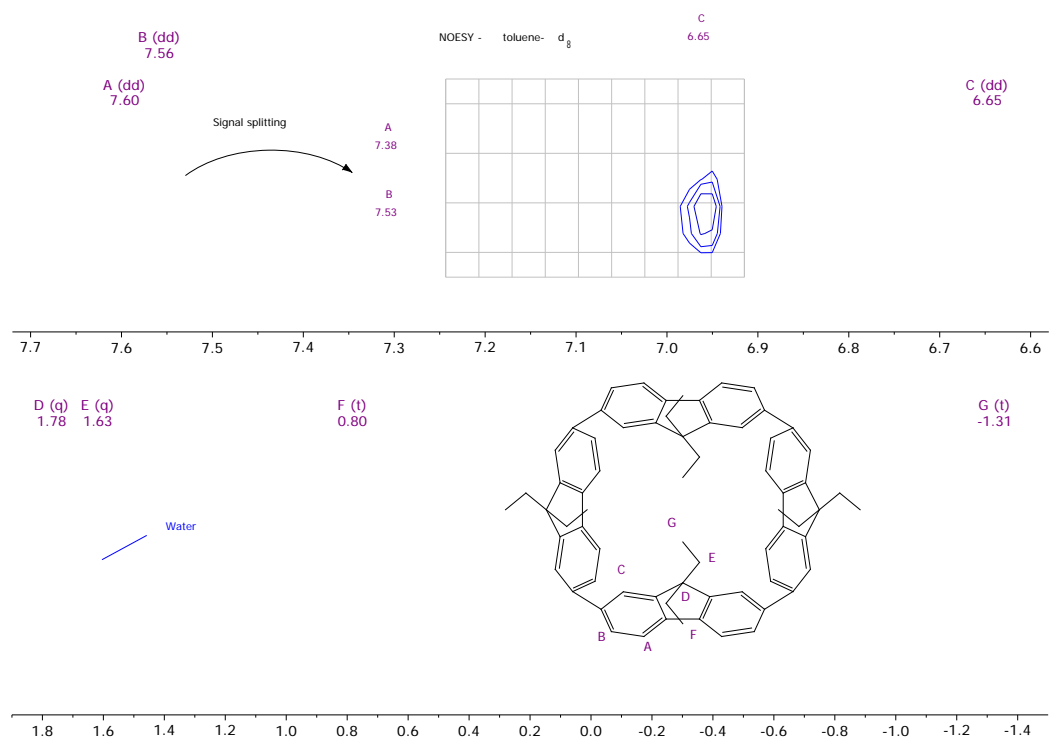

Figure 1. Relevant parts of the ${ }^{1} \mathrm{H}$ NMR spectrum of [4]C-diEt-F in $\mathrm{CD}_{2} \mathrm{Cl}_{2}$ and inset displaying a zoom of the NOESY spectrum in toluene- $d_{8}$ (full spectra can be found in SI).

The ${ }^{1} \mathrm{H}$ NMR (See Figure 1 and SI) of [4]C-diEt-F displays in the aromatic region an upfield shifted doublet of doublets (long range coupling with $\mathrm{H}^{\mathrm{A}}$ and $\mathrm{H}^{\mathrm{B}}$ ) corresponding to proton $\mathrm{H}^{\mathrm{C}}$ and two doublet of doublets shifted further downfield corresponding to proton $\mathrm{H}^{A}$ and $\mathrm{H}^{\mathrm{B}}$ (short range coupling with each other and long range coupling with $\mathrm{H}^{\mathrm{C}}$ ). This profile is in accordance with a highly symmetrical molecule possessing either an $\alpha \beta \alpha \beta$ or an $\alpha \alpha \alpha \alpha$ topology. In order to discriminate between the two, a NOESY experiment was carried out (see inset of Figure $1 \& \mathrm{SI}$ ). As the signals of $\mathrm{H}^{\mathrm{A}}$ and $\mathrm{H}^{\mathrm{B}}$ are overlapping in both $\mathrm{CD}_{2} \mathrm{Cl}_{2}$ and $\mathrm{CDCl}_{3}$, toluene- $d_{8}$ which enables a full separation of these signals, was found suitable. The NOESY spectrum shows very clearly the exclusive through-space coupling between proton $\mathrm{H}^{\mathrm{B}}$ and $\mathrm{H}^{\mathrm{C}}$, hence pointing to the all anti conformer $\alpha \beta \alpha \beta$. It should be noted that variable temperature NMR studies from $238 \mathrm{~K}$ to $378 \mathrm{~K}$ do not show any significant modifications of the ${ }^{1} \mathrm{H}$ spectrum. This highlights that (i) we are not in presence of a time-averaged dynamic structure and (ii) there is no possible inversion of the fluorene units and hence the other rotamers ( $\alpha \alpha \alpha \beta, \alpha \alpha \alpha \alpha$ and $\alpha \alpha \beta \beta$ isomers) cannot be obtained by thermal input in this temperature range. The presented ${ }^{1} \mathrm{H}$ NMR spectra of [4]CdiEt-F show the same layout in the aromatic region as its dimethyl and dipropyl analogues. The shielding of $\mathrm{H}^{\mathrm{C}}$ is attributed to the ring current of the macrocycle to which it is exposed. ${ }^{[26]}$ It suggests the fluorene units are tilted the bridge side towards the inside of the ring (as observed in single-crystal X-ray crystallography, see discussion below). Therefore, comparing the chemical shifts of $\mathrm{H}^{\mathrm{C}}$ between the three [4]cyclofluorenes in $\mathrm{CDCl}_{3}$ (see $\mathrm{SI}$ for spectra) can give us an indication of the relative degree of tilt. We note that the signal of $\mathrm{H}^{\mathrm{C}}$ is quite significantly upfield shifted for [4]C-diEt-F compared to both [4]C-diMe-F (by $0.27 \mathrm{ppm}$ ) and [4]C-diPr-F (by $0.11 \mathrm{ppm}$ ). This feature matches the observation of the stronger torsion angles between the fluorene units for [4]C-diEt-F compared to [4]C-diPr-F in their crystal structures (see below). On the other hand, the chemical shifts of $\mathrm{H}^{\mathrm{A}}$ and $\mathrm{H}^{\mathrm{B}}$, both pointing to the outside of the ring, are found to be almost identical for all molecules. Looking at the aliphatic region, it is clear that while all four fluorene units are equivalent, the two ethyl chains bared by one fluorene unit are not. If this feature seems to match what is reported for both the dimethyl and dipropyl [4]cyclofluorenes, our system displays however a striking difference. Indeed, a triplet corresponding to the methyl protons of one ethyl chain is dramatically upfield shifted to $-1.31 \mathrm{ppm}$, while the other appears at 0.80 $\mathrm{ppm}$. These methyl protons essentially act as probes $^{[27]}$ of the macrocyclic ring current. Yamago et al have reported an analogue effect ${ }^{[26]}$ but with a tetracarbazole ring bearing a covalent alkyl bridge purposely designed to pass across the centre of the ring. In our case, it appears that one of the two ethyl chains of each fluorene unit is positioned towards the centre of the ring, exposing its methyl group the strong shielding effect of the ring current, as displayed by the X-ray crystal structure detailed below. 


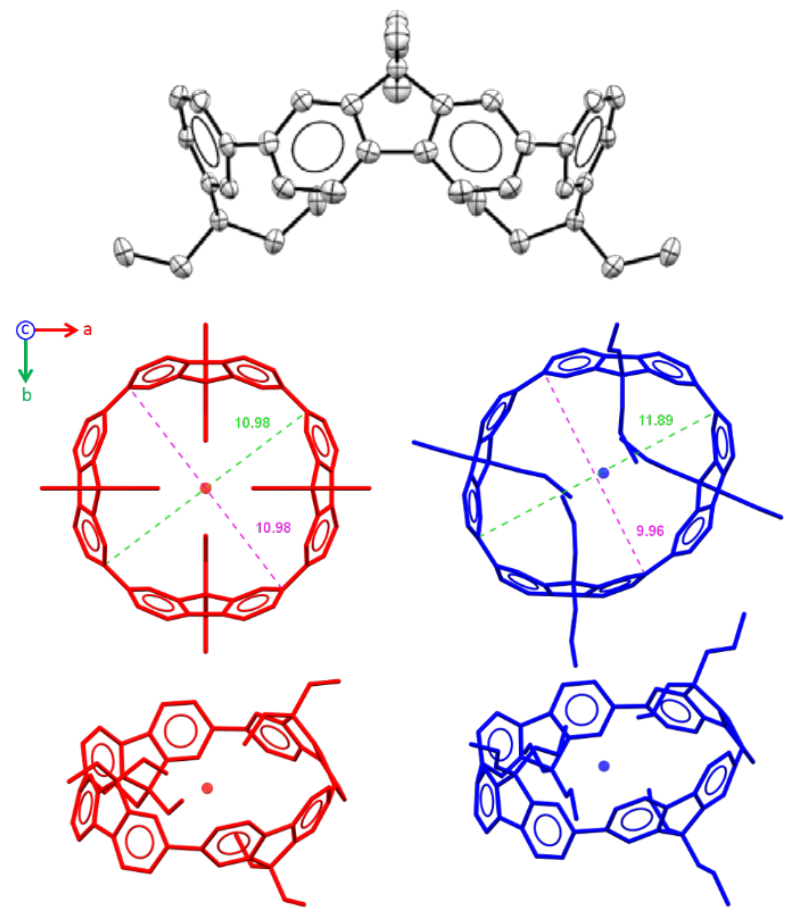

Figure 2. X-Ray crystal structure representations of [4]C-diEt-F (Top and red) and [4]C-diPr-F (blue) reported by Huang and coworkers (CCDCl 1031896) $)^{[22,28]}$ with distances in Ångström.

X-Ray diffraction of single crystals of [4]C-diEt-F (Figure 2), which were obtained by slow diffusion of cyclohexane in a concentrated solution of DCM, reveals the $\alpha \beta \alpha \beta$ conformation compatible with the NMR discussion. The first striking structural characteristic is the high degree of symmetry of the molecule. [4]C-diEt-F crystallises in a $P 42 / n m c$ space group corresponding to the point group $4 / \mathrm{mmm}$ of a ditetragonal dipyramidal class. Thus, in [4]C-diEt-F, the opposite fluorenes are remarkably arranged in a perfectly eclipsed conformation. The upper part of each fluorene (the diethyl bearing bridge side) is tilted towards the centre of the ring. The shortest distance, $8.69 \AA$, between two cofacial phenyl units is hence measured between the two $\mathrm{C} 1$ carbon atoms (see $\mathrm{SI}$ ). Then, the corresponding distance between two cofacial carbon atoms gradually increases from C2-C2 $(d=8.74 \AA)$, to C3-C3 $(d=10.19 \AA)$ and finally to C4-C4 $(d=11.28 \AA)$. Due to this inclination, the bridges are also relatively close to each other with a distance between two opposite C9 carbons of $9.20 \AA$. The present eclipsed molecular arrangement appears different from the only cyclic tetrafluorene crystal structure reported to date, that is [4]C-diPr-F (Figure 2, right). ${ }^{[22]}$ Indeed, [4]C-diPr-F, which also presents a $\alpha \beta \alpha \beta$ conformation, forms a distorted ellipsoidal ring (radii $=9.96$ and $11.89 \AA ̊ \AA$ ) whereas [4]C-diEt-F forms a perfect circle (radius $=$ $10.98 \AA$ A). This variation could be assigned to the different steric hindrance induced by the ethyl and propyl chains: it would seem that while the propyl chains are long enough to disturb each other and distort the macrocycle, the ethyl chains are just the right size to lock the macrocycle into a perfectly eclipsed ring. Thus, the shortening of the bridgeheads by only one carbon (ethyl vs propyl) seems to have consequences on the molecular arrangement. In addition, the deformation of the fluorene backbones is slightly different from that observed for the propyl analogue [4]C-diPr-F and deserves to be precisely stressed out herein (See SI for figures). First, the distance between the $\mathrm{C} 2$ and $\mathrm{C} 7$ carbon atoms of a fluorene unit can give an idea of its out-ofplane distortion, which is one of the chief factors at the origin of the specific properties of CPP and CPP-like molecules. ${ }^{[12]}$ For [4]C-diEt-F, this distance is equal for each fluorene unit (6.64 $\AA$ ) whereas it ranges from 6.58 to $6.72 \AA$ for [4]C-diPr-F. Next, the bend angle (which takes into account the folding of the phenyl units unlike the dihedral angle between two phenyl planes $)^{[29]}$ of the fluorene is measured to be $53.94^{\circ}$ for [4]C-diEt-F and ranges from $47.41^{\circ}$ to $58.09^{\circ}$ (mean of $53.30^{\circ}$ ) for [4]C-diPr-F. The torsion angle between two adjacent fluorene is also a very important parameter and appears herein as high as $41.53^{\circ}$ for [4]C-diEt-F, when it ranges from $31.60^{\circ}$ to $40.20^{\circ}$ with a mean of $34.86^{\circ}$ for [4]C-diPr-F. To summarise, the fluorene units are homogeneously more deformed in the present [4]C-diEt-F than in the dipropyl cyclofluorene [4]C-diPr-F. 
Finally and as mentioned above, we note that the interior ethyl chains of [4]C-diEt-F are placed as such as they are aiming at the centroid of the macrocycle, angled towards the centre of the ring as permitted by the strong torsion angle between the fluorene units. On the other hand, the interior propyl chains of [4]C-diPr-F have their end methyl groups aiming away from the centroid of the macrocycle (Figure 2), along both the $c$ axis and ab plane, avoiding each other two by two.
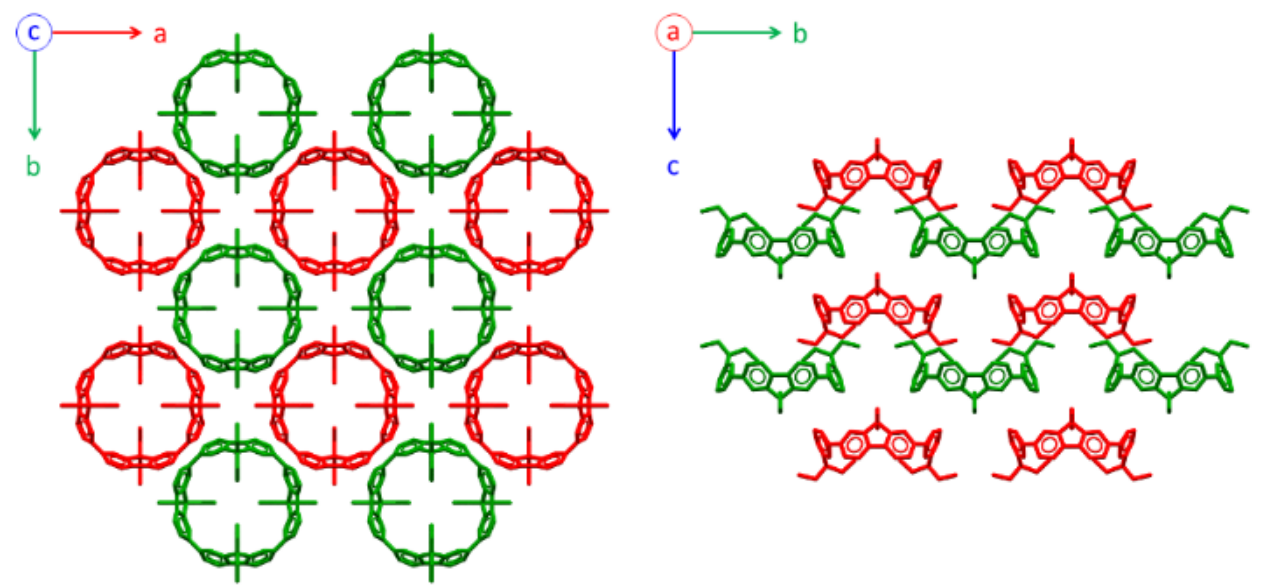

Figure 3. Packing diagram of [4]C-diEt-F (left: view along c axis, right: view along a axis).

The analysis of the molecular packing of [4]C-diEt-F shows a pseudo-tubular arrangement along the $c$ axis (Figure 3). Indeed, the molecules are spread into two alternate layers all with their central cavity along the same direction. On the other hand, a herringbone packing was reported for [4]C-diPr-F. While we are aware that the crystallisation conditions can have an influence on the packing structure of nanorings, ${ }^{[30]}$ in our case the ethyl chains still seem to play an important role on the supramolecular arrangement (See SI for detailed figures): they are involved in all the short contacts observed in the packing diagram. Thus, one can note that there is a very short distance, between the hydrogen atoms $\left(\mathrm{d}_{\mathrm{H}-\mathrm{H}}=2.39 \AA\right.$, inferior to the sum of the van der Waals radii $\left.{ }^{[31]}\right)$ and between the carbon atoms ( $d_{c-c}=3.45 \AA$, only slightly longer than the sum of the van der Waals radii) of the facing methyl groups pointing out to the exterior of the ring. In addition, the carbon atoms of these methyl groups are also involved in relatively short contacts with the hydrogen atoms in position 4 of the surrounding fluorene units $\left(\mathrm{d}_{\mathrm{C}-\mathrm{H}}=2.98 \AA\right)$. To conclude, the interior ethyl chains seem to have effect on the molecular arrangement while the exterior chains seem to drive the supramolecular arrangement, highlighting the potential tunability of the structural properties through the fluorene bridges.
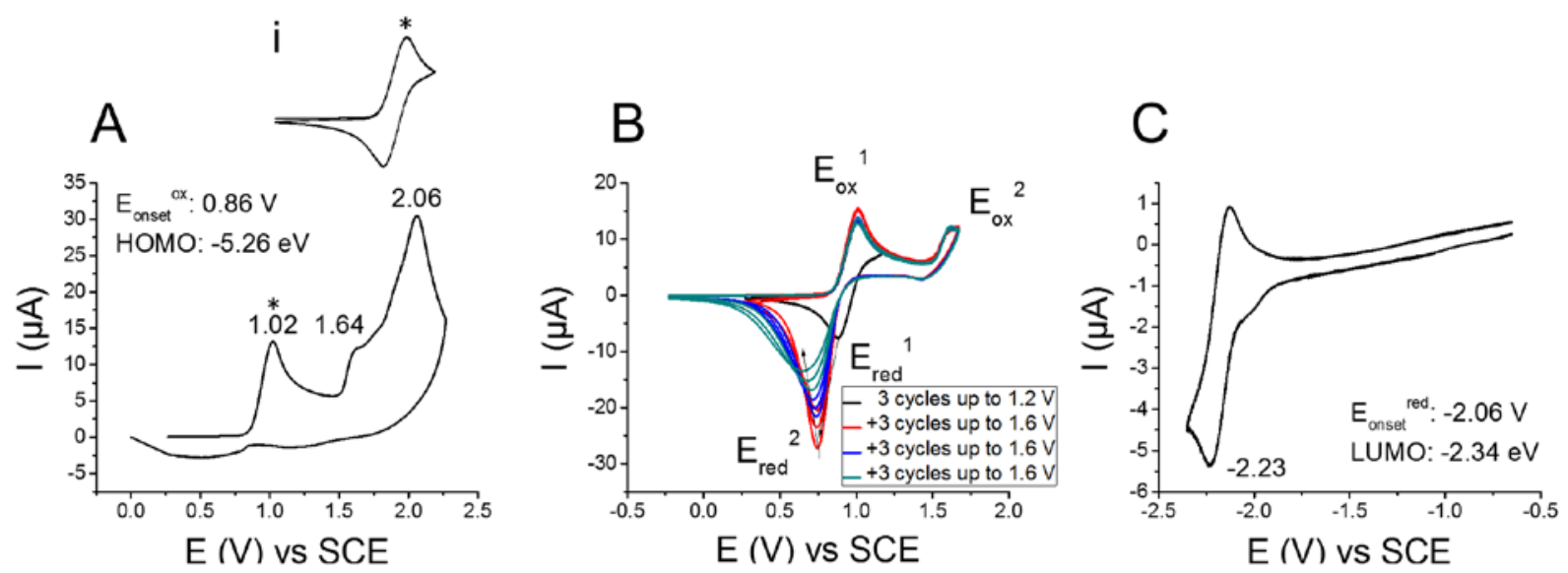

Figure 4. Cyclic voltammetry recorded on platinum working disk electrode $(\varnothing=1 \mathrm{~mm})$ in dry DCM (A-B) or in dry DMF (C) $+0.2 \mathrm{~mol} . \mathrm{L}^{-1} \mathrm{Bu}_{4} \mathrm{NPF}_{6}\left(\right.$ scan rate $\left.0.1 \mathrm{~V} . \mathrm{s}^{-1}\right)$ in presence of [4]C-diEt-F $\left(2.67 \times 10^{-3} \mathrm{~mol} . \mathrm{L}^{-1}\right)$. 
Electrochemical analyses of [4]C-diEt-F were performed in DCM (or in DMF) + $0.2 \mathrm{M} \mathrm{Bu}_{4} \mathrm{NPF}_{6}$ (Figure 4). Cyclic voltammetry (CV) recorded between 0.0 and $2.5 \mathrm{~V}$ in DCM (Figure 4A) exhibited three successive oxidation processes with maxima (or shoulder (sh)) recorded at 1.02, 1.64 (sh) and $2.06 \mathrm{~V}$ vs SCE. The HOMO calculated from the onset potential of the first oxidation ${ }^{[32]}\left(E_{\text {onset }}{ }^{o x}=0.86 \mathrm{~V}\right)$ is lying at $-5.26 \mathrm{eV}$. As depicted in inset $i$ of Figure $4 \mathrm{~A}$, the first oxidation was nicely reversible. Interestingly, recurrent sweeps recorded up to $1.67 \mathrm{~V}$ (Figure 4B) lead to a modification of the successive CVs mainly for the reduction processes whereas the oxidation processes remained similar. Indeed, if the second oxidation process is less intense than the first, the reduction process recorded after the two oxidations is clearly more intense and shifted to less anodic potentials compared to those recorded after only the first oxidation. The sharp reverse reduction peaks are consistent with precipitation of charged species on the electrode surface and their subsequent cathodic stripping in the return direction of the scan with the regeneration of [4]C-diEt-F. Nevertheless, the present CVs explorations do not allow us to assign with confidence the nature of the charged species deposited on the electrode upon oxidation, including the second oxidation process. Additional experiments (chemical oxidation, spectroelectrochemistry) are currently under investigations to precisely determine the nature of these charged species.

Upon reduction in DCM (see $\mathrm{SI}$ ), an irreversible reduction was observed with an onset reduction potential at $2.10 \mathrm{~V}$, different from the irreversible reduction observed in absence of [4]C-diEt-F $\left(E_{\text {onset }}{ }^{\text {red }}=-2.56 \mathrm{~V}\right)$. In order to investigate this reduction process, the CV was recorded in DMF (Figure $4 \mathrm{C}$ ) allowing the detection of a clear reversible reduction wave $(E=-2.23 \mathrm{~V})$, which possesses a similar onset potential than that measured in DCM. The resulting LUMO calculated from the onset reduction potential in either DMF or DCM is lying at $-2.32 \mathrm{eV}$. The resulting electrochemical energy gap is hence determined to be $2.94 \mathrm{eV}$. Thus, compared to the two other [4]cyclofluorene electrochemical studies reported to date in literature, the present points the existence of two additional oxidation waves at higher potential values. Moreover, our cathodic exploration in DMF which enables a wider electrochemical window shows a reversible reduction wave not reported neither for the propyl (irreversible reduction in DCM) nor for the methyl analogue (no reduction visible in THF). ${ }^{[21-22]}$
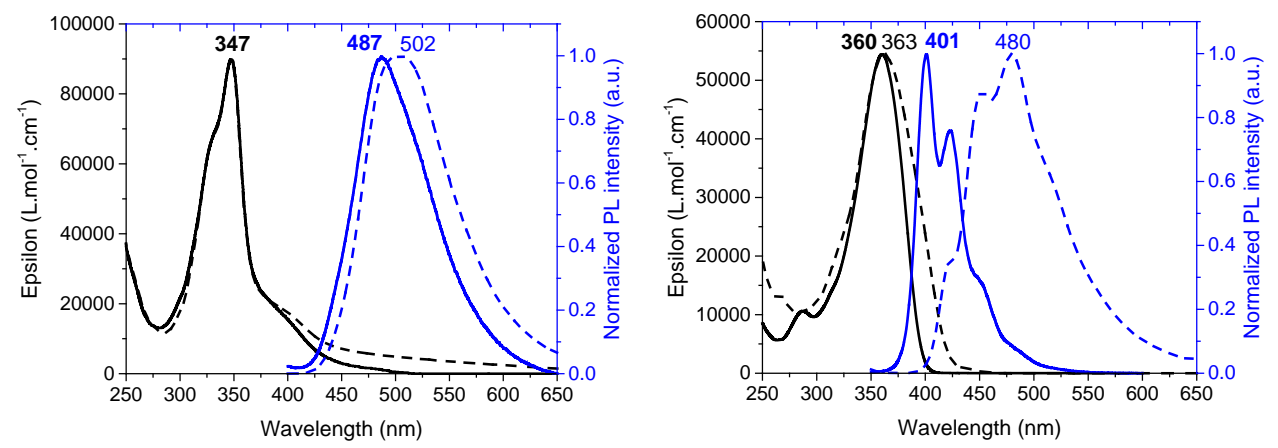

Figure 5. Combined absorbance (black) and emission (blue, $\lambda$ exc $=340 \mathrm{~nm}$ ) spectra of [4]C-diEt-F (left) and [4]L-diEt-F (right) in cyclohexane (solid lines) and in spin-coated film (THF $1 \mathrm{mg} / \mathrm{mL}$, dashed lines). Absorption spectra in thin film are normalized to their respective solution absorption maxima.

The photophysical properties of [4]C-diEt-F have also been investigated (Figure 5, left). The absorption spectrum appears to be very similar to that described in literature for other cyclofluorenes, with an absorption maxima at $347 \mathrm{~nm}$ and two shoulder peaks at 330 and $395 \mathrm{~nm}$. Indeed, the HOMO $\rightarrow$ LUMO transition is symmetry forbidden and only a very weak experimental band is observed. In emission spectroscopy, [4]C-diMeF, [4]C-diEt-F and [4]C-diPr-F display spectra similar in shape constituted of a large and unresolved band, very different from the well-defined spectra of their linear counterparts represented here by [4]L-diEt-F (Figure 5, right). However, a remarkable blue shift of $22 \mathrm{~nm}$ between the emission maxima of [4]C-diEt-F ( $\lambda_{\max }=490 \mathrm{~nm}$ in THF, $492 \mathrm{~nm}$ in chloroform, see SI) and both [4]C-diPr-F $\left(\lambda_{\max }=512 \mathrm{~nm}\right.$ in THF) ${ }^{[22]}$ and [4]C-diMe-F $\left(\lambda_{\max }=514\right.$ $\mathrm{nm}$ in chloroform) ${ }^{[21]}$ was detected. While we would expect all three [4]cyclofluorenes to exhibit the same emission, our example [4]C-diEt-F, which is in-between the two others in respect of their alkyl chain sizes, displays a specific behaviour. Thus, substituting the fluorene bridges specifically with ethyl groups induces a blue shift of the emission maximum most likely due to the resulting structural arrangement of the fluorene 
units. This modulation of the emission wavelength by such a modification of the chain length is not found with the linear oligofluorenes family and hence appears as a specific characteristic of the cyclofluorenes family.

In thin film, no relevant differences are observed for the absorption spectra compared to solution. In emission, a strong red shift (>50 nm) is observed for [4]L-diEt-F, most likely due to $\pi-\pi$ stacking. However, [4]CdiEt-F does not follow the same trend with only a small red shift of $15 \mathrm{~nm}$ between solution and thin film. This feature suggests that cyclofluorenes are less sensitive to aggregation than their linear analogues (this effect will be stressed by the quantum yields presented below), which should allow a better control of the emission wavelength in the solid state, key point for future optoelectronic applications.

The absolute quantum yield QY of [4]C-diEt-F in cyclohexane solution was measured at 0.25 , a value almost identical to that obtained with quinine sulfate as a reference (0.24). [4]L-diEt-F in the same conditions displays a QY of 1 (0.92 with quinine sulfate as a reference), showing that, in dilute solution, linear oligofluorenes are significantly more efficient fluorophores than their cyclic analogues. However, in thin film, we note a decrease of the QY from 1 to 0.11 for [4]L-diEt-F. This feature is assigned to the stacking of the fluorene units in the solid state and is in accordance with the red shift observed in fluorescence (see above). Remarkably, [4]C-diEt-F displays a different behaviour as its QY is decreased by half (0.12). Thus, the QY is decreased by a factor of ca 10 for [4]L-diEt-F and only by a factor 2 for [4]C-diEt-F in thin film compared to solution. This finding appears highly appealing for the future design of fluorene nanorings for solid state optoelectronics.

The fluorescence decay curve of [4]C-diEt-F measured in cyclohexane $\left(\lambda_{\text {exc }}=310 \mathrm{~nm}\right.$, See SI) provides a lifetime of $7.9 \mathrm{~ns}$, which is longer than the corresponding lifetime of its linear analogue [4]L-diEt-F, found to be below $1 \mathrm{~ns}$. The radiative rate constant $\mathrm{k}_{\mathrm{r}}$ of [4]C-diEt-F is calculated to be $3.0 \times 10^{7} \mathrm{~s}^{-1}$ being three times lower than the non-radiative rate constant $\mathrm{k}_{\mathrm{nr}}, 9.6 \times 10^{7} \mathrm{~s}^{-1}$. [4] L-diEt-F displays a $\mathrm{k}_{\mathrm{r}}>9.2 \times 10^{8} \mathrm{~s}^{-1}$ and a $\mathrm{k}_{\mathrm{nr}}>8.0 \times 10^{7} \mathrm{~s}^{-1}$. Thus, one can note that from [4]L-diEt-F to [4]C-diEt-F, $k_{r}$ is decreased by almost two orders of magnitude whereas $k_{n r}$ remains similar. Therefore, in solution, the decrease of $Q Y$ in [4]C-diEt-F is caused by its much lower electronic transition moment, but not by more efficient internal conversion processes.

It is only the dawn of the molecular nanoring research field, and many directions have already been taken in order to explore the potential of these new molecular objects. The influence of the ring size and of the constituting units on the structural, electronic, physical, chiral and encapsulating properties have already shown the fantastic diversity of nanorings and their unusual characteristics. ${ }^{[2]}$ In the present work, we report a feature never discussed to date through the example of the [4]cyclofluorenes family. The modification of the length of the alkyl chains has indeed consequences on the structural arrangement of the ring in the crystal state: compared to [4]C-diPr-F, [4]C-diEt-F is not distorted and the fluorene units display a perfectly eclipsed conformation. A pseudo-tubular solid state arrangement is also observed in the packing diagram. We believe these features reflect the structural characteristics of [4]C-diEt-F in solution as the NMR study would suggest. Finally, the resulting specific fluorescence in regards to the two other published [4]cyclofluorenes highlights the potential tuning of properties through alkyl chain engineering of the bridgeheads. As the arrangement of $\pi$ systems is deeply linked to the resulting electronic properties, this finding may be used in the future to design other cyclofluorenes with specific properties notably for organic electronics. We are currently working in this direction.

\section{Supporting Information.}

Experimental Section, additional structural and photophysical data, molecular modelling details, 2D NMR studies and copies of NMR and HRMS spectra.

Keywords: cyclofluorene, nanorings, fluorescence, structure-properties relationship studies, fluorescence.

Conflict of Interest: "The authors declare no conflict of interest." 


\section{ACKNOWLEDGMENTS}

This project has received funding from the European Union's Horizon 2020 research and innovation program under grant agreement No 699648 (FRODO Project). We thank the CDFIX and CRMPO (Rennes), the ANR 'Men In Blue' ( ${ }^{\circ}$ 14-CE05-0024) for a studentship (LJS).

\section{REFERENCES}

[1] R. Jasti, J. Bhattacharjee, J. Neaton and C. R. Bertozzi, J. Am. Chem. Soc. 2008, 130, 17646-17647.

[2] E. R. Darzi and R. Jasti, Chem. Soc. Rev. 2015, 44, 6401-6410.

[3] H. Omachi, Y. Segawa and K. Itami, Acc. Chem. Res. 2012, 45, 1378-1389.

[4] M. R. Golder and R. Jasti, Acc Chem Res 2015, 48, 557-566.

[5] H. Takaba, H. Omachi, Y. Yamamoyo, J. Bouffard and K. Itami, Angew. Chem. Int. Ed. 2009, 48, 6112-6116.

[6] S. Yamago, Y. Watanabe and T. Iwamoto, Angew. Chem. Int. Ed. 2010, 49, 757-759.

[7] S. E. Lewis, Chem. Soc. Rev. 2015, 44, 2221-2304.

[8] T. Iwamoto, E. Kayahara, N. Yasuda, T. Suzuki and S. Yamago, Angew. Chem. Int. Ed. 2014, 53, 6430-6434.

[9] H. Jia, Y. Gao, Q. Huang, S. Cui and P. Du, Chem. Commun. 2018, 54, 988-991.

[10] H.-W. Jiang, T. Tanaka, H. Mori, K. H. Park, D. Kim and A. Osuka, J. Am. Chem. Soc. 2015, 137, 2219-2222.

[11] Q. Chen, M. T. Trinh, D. W. Paley, M. B. Preefer, H. Zhu, B. S. Fowler, X.-Y. Zhu, M. L. Steigerwald and C. Nuckolls, J. Am. Chem. Soc. 2015, 137, 1228212288.

[12] Y. Segawa, A. Kukazawa, S. Matsuura, H. Omachi, S. Yamaguchi, S. Irle and K. Itami, Org. Biomol. Chem. 2012, 10, 5979-5984.

[13] M. Fujitsuka, C. Lu, T. Iwamoto, E. Kayahara, S. Yamago and T. Majima, J. Phys. Chem. A 2014, 118, 4527-4532.

[14] M. Ball and C. Nuckolls, ACS Cent. Sci 2015, 1, 416-417.

[15] M. Ball, Y. Zhong, B. Fowler, B. Zhang, P. Li, G. Etkin, D. W. Paley, J. Decatur, A. K. Dalsania, H. Li, S. Xiao, F. Ng, M. L. Steigerwald and C. Nuckolls, J. Am. Chem. Soc. 2016, 138, 12861-12867.

[16] A. C. Grimsdale, K. L. Chan, R. E. Martin, P. G. Jokisz and A. B. Holmes, Chem. Rev. 2009, 109, 897-1091.

[17] X. Yang, X. Xu and G. Zhou, J. Mater. Chem. C 2015, 3, 913-944.

[18] C. Poriel and J. Rault-Berthelot, J. Mater. Chem. C 2017, 5, 3869-3897

[19] M. Romain, D. Tondelier, J.-C. Vanel, B. Geffroy, O. Jeannin, J. Rault-Berthelot, R. Métivier and C. Poriel, Angew. Chem. Int. Ed. 2013, 52, $14147-14151$.

[20] L. Sicard, C. Quinton, J.-D. Peltier, D. Tondelier, B. Geffroy, U. Biapo, R. Métivier, O. Jeannin, J. Rault-Berthelot and C. Poriel, Chem. Eur. J. 2017, 23, 7719-7723.

[21] E. Kayahara, R. Qu, M. Kojima, T. Iwamoto, T. Suzuki and S. Yamago, Chem. Eur. J. 2015, 21, 18939-18943.

[22] Y.-Y. Liu, J.-Y. Lin, Y.-F. Bo, L.-H. Xie, M.-D. Yi, X.-W. Zhang, H.-M. Zhang, T.-P. Loh and W. Huang, Org. Lett. 2016, 18, 172-175.

[23] S. Yamago, E. Kayahara and T. Iwamoto, Chem. Rec. 2014, 14, 84-100.

[24] S. Hitosugi, W. Nakanishi, T. Yamasaki and H. Isobe, Nat. Commun. 2011, 2, 492.

[25] M. Fujita, O. Sasaki, T. Mitsuhashi, T. Fujita, J. Yazaki, K. Yamaguchi and K. Ogura, Chem. Commun. 1996, 1535-1536.

[26] Y. Kuroda, Y. Sakamoto, T. Suzuki, E. Kayahara and S. Yamago, J. Org. Chem. 2016, 81, 3356-3363.

[27] N. H. Martin, J. D. Brown, K. H. Nance, H. F. Schaefer, P. v. R. Schleyer, Z.-X. Wang and H. L. Woodcock, Org. Lett. 2001, 3, 3823-3826.

[28] C. R. Groom, I. J. Bruno, M. P. Lightfoot and S. C. Ward, Acta Cryst. B 2016, 72, 171-179.

[29] G. J. Bodwell, J. J. Fleming and D. O. Miller, Tetrahedron 2001, 57, 3577-3585.

[30] T. Fukushima, H. Sakamoto, K. Tanaka, Y. Hijikata, S. Irle and K. Itami, Chem. Lett. 2017, 46, 855-857.

[31] A. Bondi, J. Phys. Chem. 1964, 68, 441-451.

[32] A. P. Kulkarni, C. J. Tonzola, A. Babel and S. A. Jenekhe, Chem. Mater. 2004, 16, 4556-4573.

\section{Table of Contents}

We report the unforeseen effect of a chain length modification (substitution of the bridgeheads with ethyl chains) on the structural and emission properties of a new example of a cyclic tetrafluorene, namely the [4]cyclo-9,9-diethyl-2,7fluorene ([4]C-diEt-F).

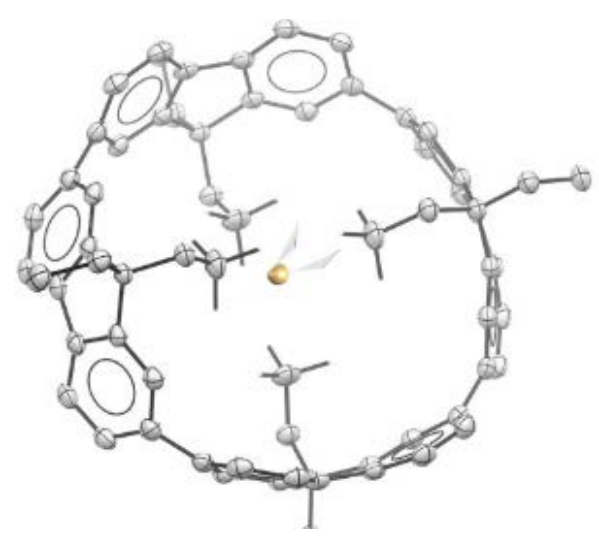

